\title{
Multiple Trauma Patient Safety in the Emergency Care: Scoping Review

\begin{abstract}
Andréa Tayse de Lima Gomes ${ }^{1}$, Flávia Barreto Tavares Chiavone², Manacés dos Santos Bezerril ${ }^{3}$, Larissa de Lima Ferreira ${ }^{2}$, Micheline da Fonseca Silva ${ }^{1}$, Alcides Viana de Lima Neto ${ }^{4}$, Viviane Euzébia Pereira Santos ${ }^{5}$
\end{abstract}

\section{Abstract}

Background: To summarize the scientific evidence on the influence of safe nursing care to multiple trauma patients in the emergency care.

Methods: Scoping review using the strategy P (Population) C (Concept) C (Context) and performed in the online databases: PubMed, Cumulative Index to Nursing and Allied Health Literature, Scopus and Web of Science, in June 2016.

Results: The sample was composed of 43 articles, with most of them being descriptive $(n=35 ; 81.4 \%)$, quantitative approach $(n=32$; $74.4 \%)$, level of evidence $4(n=35 ; 81.4 \%)$ and recommendation grade $A(n=40 ; 93.0 \%)$. The structure pointed to the availability of equipment for performing imaging and laboratory functioning $(n=18$; $41.9 \%)$. The process highlighted the completion of the screening in the emergency department $(n=20 ; 46.5 \%)$. The result showed the great waiting time of patients to treatment $(n=4 ; 9.3 \%)$ and dissatisfaction of professionals regarding the care provided and the working conditions $(n=4 ; 9.3 \%)$.

Conclusions: The triad structure-process-result of the emergency services have problems able to compromise the security of critically ill patients.
1 Nurse, Master degree student by the Graduate Program in Nursing of the Federal University of Rio Grande do Norte. Scholarship CAPES/DS. Natal, Rio Grande do Norte, Brazil.

2 Nursing Student at the Federal University of Rio Grande do Norte. Scholarship CNPq. Natal, Rio Grande do Norte, Brazil.

3 Nursing Student at the Federal University of Rio Grande do Norte. Natal, Rio Grande do Norte, Brazil.

4 Nurse, Master degree student by the Graduate Program of the Federal University of Rio Grande do Norte. Natal, Rio Grande do Norte, Brazil.

5 Nurse. Ph.D. in Nursing. Graduate and Post-Graduate Professor in Nursing at the Federal University of Rio Grande do Norte. Scholarship of Research Productivity CNPq (PQ2 2016-2019). Natal, Rio Grande do Norte, Brazil.

\section{Contact information:}

Andréa Tayse de Lima Gomes.

Address: 76 Severino Soares St., DixSept Rosado, Natal, Rio Grande do Norte, Brazil. ZIP CODE: 59.052-450.

झ andrea.tlgomes@gmail.com

\section{Keywords}

Multiple Trauma; Nursing; Patient Safety; Emergencies. 


\section{Introduction}

Mainly due to traffic accidents and violence, traumatic injuries are a serious problem of public health worldwide. This type of injury is responsible for the death of approximately 5.8 million people annually. This reality represents $10.0 \%$ of deaths worldwide, whose rate is higher than the death rates from malaria, tuberculosis and HIVIAIDS combined. Furthermore, $90.0 \%$ of deaths associated with the trauma occur in underdeveloped and developing countries [1-3].

Thus, it is ensured that early or first-hour interventions ("golden hour") after trauma may minimize secondary damage and reduce morbidity in severely injured patients to increase the chances of survival of multiple trauma [4]. Therefore, there is a growing need to provide proper, organized and safe treatment focused for this type of emergency [5] to reduce to a minimum the risk of post-treatment sequel and death.

In this sense, the professionals of the emergency service must provide a proven safe and high-quality care. This safe care is the absence of unnecessary harm or potential harm associated with healthcare [6-7].

Thus, the emergency unit is admittedly characterized by the provision of high-complexity care and requires a coordinated approach to professional care quality assurance [8]. Thus, health institutions, especially the emergency service must undergo periodic evaluations to ensure improved quality of care for situational analysis and recognition of professionals and managers on the need for structural and procedural changes to the purpose of obtaining better results.

In this perspective, Avedis Donabedian prepared an evaluation model of health quality based on three pillars: structure, process, and result. The structure is the physical, human, material and financial resources for health care; the process refers to the relationship between health professionals and patients, since the search for the diagnosis, treatment, and appropriate care; and finally, the result concerns the final product of the care provided, represented by the effectiveness and efficiency of actions and the level of satisfaction of patients, professionals, and managers. [9]

Therefore, it is clear the importance of the quality of emergency services to meet the multiple trauma patients. Therefore, to guide this study, the research question was "how nursing care can influence the safety of the multiple trauma patients in an emergency situation?" It aimed to summarize the scientific evidence on the influence on safe nursing care for multiple trauma patients in emergency care to respond to the proposed question.

\section{Methods}

This is a scoping review based on the method proposed by the Joanna Briggs Institute (JBI), because this model considers the evidence-based practice as the guide clinical decision, which includes the best available evidence, the context in which care is done, the patient preference and the judgment of health professionals. Thus, the scientific evidence can include speech, experience and research. The synthesis of this evidence includes the theory, methodology and scoping review, which is the method applied in this research. The JBI describes this type of review in five basic steps: 1) identification of the research question; 2) identification of relevant studies; 3) selection of the studies; 4) analysis of the data; and, 5) grouping, synthesis and presentation of data [10-11].

The research question, the objective of the study and the descriptors were established according to the combination mnemonic P (Population) C (Concept) $C$ (Context). Thus, the step 1 of this review about the definition of the research question, resulted in the following guiding question: "how nursing care can influence the safety of the multiple trauma patients in an emergency situation?".

The second step consisted of two periods of research in electronic databases. The first period co- 
Figure 1: Flowchart concerning the selection studies of the databases, 2016.

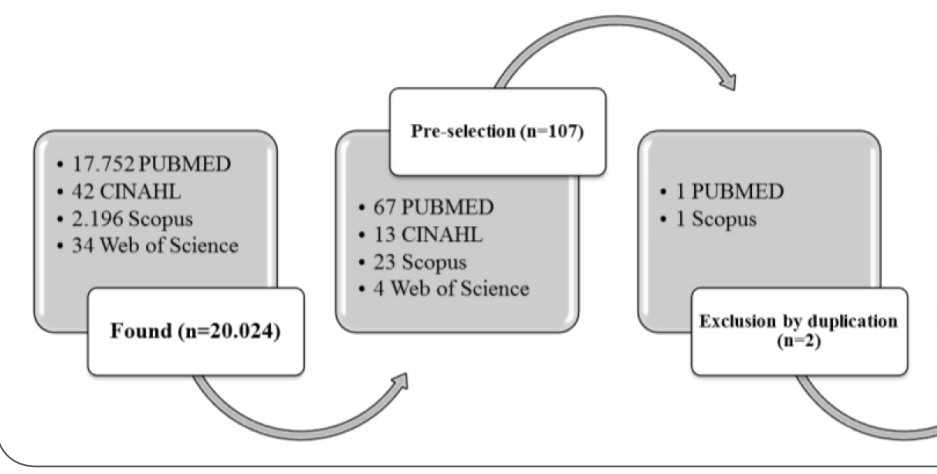

rresponded to the selection of keywords and synonyms used in published and available studies on the databases indicated by the JBI manual [11] - National Library of Medicine (PubMed) and Cumulative Index to Nursing and Allied Health Literature (CINAHL).

Therefore, there were indexed descriptors adopted in the controlled vocabulary of Medical Subject Heading Terms (MeSH): P - "Multiple Trauma" (\#1), C - Nursing (\#2) / "Patient Safety" (\#3), C - Emergencies (\#4). Furthermore, the truncation " "was applied to find the adjacent terms and the intersection were between the descriptors given by the Boolean AND operator. In this first search, there were four crosses used between the descriptors: 1) \#1 AND \#2 AND \#3; 2) \#1 AND \#3 AND \#4; 3) \#1 AND \#2 AND \#4; and, 4) \#1 AND \#3.

After the selection of descriptors and synonyms, there was the electronic search of studies in the databases PubMed, CINAHL, Scopus and Web of Science during the period 12-24 June 2016. For this, the resource truncation " "and the Boolean operators AND and OR were used, as described in the search strategy: ("Multiple Trauma" OR Trauma OR Injury OR "Multiple Injured" OR Polytrauma OR "Multi Trauma" OR "Wounds and Injuries") AND ("Patient Safety" AND Nursing OR "Emergency Nursing" OR "Nursing Staff, Hospital" OR "Nursing Care") AND (Emergencies OR "Emergency Service/ Hospital" OR "Trauma Centers" OR "Emergency Medical Services" OR "Emergency Care").

The refinement of the articles was based on the eligibility and pre-established criteria. Therefore, the

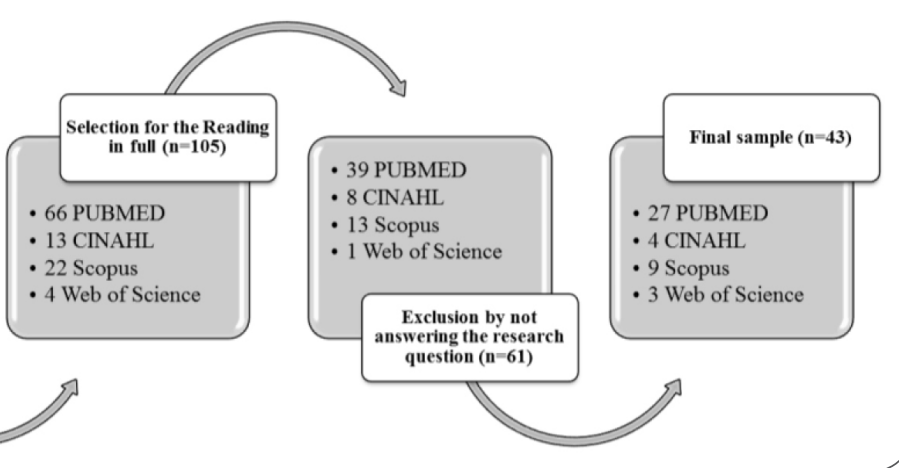

inclusion criteria were: publications available in full text electronically and aimed at the influence of the safe nursing care to multiple trauma adult patients in emergency care. Duplicate studies in editorial format, letter to the editor, review articles and opinion were deleted. It is emphasized that there was no temporal filter to the selection of studies.

In the third step of this review, the articles were pre-selected from reading the titles and abstracts and the final sample was reached based on the reading of the articles in full as the flowchart shows

\section{in Figure 1.}

The articles were analyzed (step 4) by predetermined data collection indicators, which were: database, the country where the study was conducted, year of publication, objective (s), study design, study population and sample size, level of evidence, grade of recommendation, classification as Avedis Donabedian - structure and/or process and/or results and main findings.

The level of evidence and grade of recommendation were classified according to the JBI [12-13]. Evidence levels are categorized from 1 to 5: Level 1 - Experimental studies (systematic reviews of randomized controlled trials and randomized clinical trials); Level 2 - quasi-experimental studies (systematic reviews of almost experimental, quasi-experimental controlled prospective studies and retrospective studies with control group); Level 3 - Analytical Observational studies (systematic reviews involving cohort studies, cohort studies with and without control group and case-control studies); Level 4 - Descripti- 
ve Observational studies (systematic reviews of descriptive studies, descriptive studies, sectional, case series and case study); and Level 5 - Expert opinions and investigations of banks (systematic reviews of expert opinions, expert consensus and banks investigations or opinion of a single expert).

The degree of recommendation is divided into $A$ and $\mathrm{B}$ : A - strong recommendation for a particular health management strategy is: (1) evident that the desirable effects outweigh the undesirable effects; (2) when quality of evidence that supports the use of the object of study; (3) there is benefit (s) or no impact on the use of resources; and (4) the values, preferences and patient experiences were considered; and B - poor rating for a particular health strategy is classified according to: (1) the desired effects seem to overcome the undesirable effect, though not clearly explained; (2) shows evidence indicating the use of feature (s), but may be of low quality; (3) there is a benefit without any impact or with minimal impact to the detriment of the use of feature (s) and; (4) the values, preferences and experiences of patients may or may not have been considered.
Finally, the fifth step of this scoping review is the critical data analysis. The results were entered into spreadsheets available in Microsoft Excel 2010 ${ }^{\circledR}$, analyzed by descriptive statistics and presented in tables.

Moreover, the level of evidence and grade of recommendation of the discussion of this research used publications, presented by a number from 1 to 5 (evidence of the study) followed by the letter $A$ or $\mathrm{B}$ (grade of recommendation) as the classification of JBI [12-13]. That is if the level of evidence of the study is " 2 " and the degree of recommendation is " $A$ ", the representation is " $2-A$ ".

\section{Results}

The final sample consisted of 43 publications, categorized in Table 1 according to the type of study, the classification of the level of evidence (LE) and Degree of Recommendation (DR), methodological approach, reference code analysis study, article title, year and journal publishing and the country where the research was conducted.

Table 1. Summarization and categorization of findings in the studies included in the final sample, 2016.

\begin{tabular}{|c|c|c|}
\hline $\begin{array}{l}\text { Type of study } \\
\text { (LE-DR)/ } \\
\text { Approach }\end{array}$ & Code & Title/Year/Journal/Country where the research was conducted \\
\hline \multirow{10}{*}{$\begin{array}{l}\text { Descriptive } \\
(4-A) / \\
\text { Quantitative }\end{array}$} & A1 & $\begin{array}{l}\text { Journey to a safe environment: fall prevention in an emergency department at a level I trauma } \\
\text { center/2013/J Emerg Nurs/US. }\end{array}$ \\
\hline & A2 & $\begin{array}{l}\text { Core team members' impact on outcomes and process improvement in the initial resuscitation of } \\
\text { trauma patients/2016/J Trauma Nurs/US. }\end{array}$ \\
\hline & A3 & $\begin{array}{l}\text { Analysis of preventable deaths by the mechanism of injury among } 13,500 \text { trauma admissions/1991/ } \\
\text { Ann Surg/US. }\end{array}$ \\
\hline & A4 & Evaluation of emergency room triage performed by nurses/1975/Am J Public Health/US. \\
\hline & A5 & $\begin{array}{l}\text { Emergency and urgent care capacity in a resource-limited setting: an assessment of health facilities } \\
\text { in western Kenya/2014/BMJ Open/Kenya. }\end{array}$ \\
\hline & A6 & $\begin{array}{l}\text { Emergency care capacity in Freetown, Sierra Leone: a service evaluation/2015/BMC Emerg Med/ } \\
\text { Sierra Leone. }\end{array}$ \\
\hline & A7 & Transport time to trauma facilities in Karachi: an exploratory study/2008/Int J Emerg Med/Pakistan. \\
\hline & A8 & $\begin{array}{l}\text { Portrait of rural emergency departments in Québec and utilization of the provincial emergency } \\
\text { department management Guide: cross-sectional survey/2015/BMC Health Serv Res/Canada. }\end{array}$ \\
\hline & A9 & Trauma centers: an idea whose time has come/1981/J Natl Med Assoc/US. \\
\hline & A10 & Survey of the current state of emergency care in Chennai, India/2011/World J Emerg Med/India. \\
\hline
\end{tabular}


Type of study

(LE-DR)/

Approach

Code

A11

Increased mortality in adult trauma patients transfused with blood components compared with whole blood/2014/J Trauma Nurs/US

A12

parison of adherence to correctly

A13 Trauma care inside and outside business hours: comparison of process quality and outcome indicators in a German level-1 trauma center/2014/Scand J Trauma Resusc Emerg Med/Germany.

A14 Variation in emergency medical services workplace safety culture/2010/Prehosp Emerg Care/US and Canada.

A15 Emergency and trauma care in Pakistan: a cross-sectional study of healthcare levels/2015/Emerg Med J/Pakistan.

Descriptive

$(4-A) /$

Quantitative

A17

A18

A19

A20 Applying artificial neural networks to predict communication risks in the emergency department/2015/J Adv Nurs/Rome.

A21 Contributing factors to errors in Swedish emergency departments/2015/Int Emerg Nurs/Sueden.

A22 Combined quality function deployment and logical framework analysis to improve the quality of emergency care in Malta/2016/Int J Health Care Qual Assur/Malta.

A23 Trauma teams and time to early management during in situ trauma team training/2016/BMJ Open/Sweden.

A24 Trends in CT utilization in an emergency department in Taiwan: a 5-year retrospective study/2016/BMJ Open/Taiwan.

A25 How to improve vital sign data quality for use in clinical decision support systems? A qualitative study in nine Swedish emergency departments/2016/BMC Med Inform Decis Mak/Sweden.

Descriptive

(4-A)/Qualitative

Nurses' perceptions of using an evidence-based care bundle for the initial emergency nursing management of patients with severe traumatic brain injury: a qualitative study/2015/Int Emerg Nurs/Thailand.

A27 Integrating quantitative and qualitative methodologies for the assessment of health care systems: emergency medicine in post-conflict Serbia/2005/BMC Health Serv Res/Iran. 
Type of study

(LE-DR)/

Approach

Descriptive

(4-A)/Qualitative

Descritive

(4-A)/Mixed

\section{Cohort}

(3-A)/

Quantitative

Control-case $(3-$

A)/Quantitative

Control-case (3B)/Quantitative

\section{Control-case}

(3-A)/Mixed

Clinical trial

$(1-\mathrm{A}) /$

Quantitative
A28

A29

A29

A30

A31

A32

Health Serv Res/Servia.

A33 Waiting for management at the emergency department - a grounded theory study/2013/BMC Health Serv Res/Sweden.

A34 Emergency Department Trauma Redesign in a Level 1 Trauma Centre/2011/Australas Emerg Nurs J/Australia.

A3

Collaborative practices in unscheduled emergency care: role and impact of the emergency care practitioner - qualitative and summative findings/2007/ Emerg Med J/England.

A36 Evaluation of a university hospital trauma team activation protocol/2011/Scand J Trauma Resusc Emerg Med/Noruega.

A37 Validation of the modified Japanese Triage and Acuity Scale-based triage system emphasizing the physiologic variables or mechanism of injuries/2016/Int J Emerg Med/Japan.

A38 The prospective, observational, multicenter, Major Trauma Transfusion (PROMMTT) study: comparative effectiveness of a time-varying treatment with competing for risks/2013/JAMA Surg/US.

A39 The impact of the ABCDE triage in the primary care emergency department on the number of patient visits to different parts of the health care system in Espoo City/2012/BMC Emerg Med/Finland.

Increased trauma center volume is associated with improved survival after severe injury: results of a Resuscitation Outcomes Consortium Study/2014/Ann Surg/US and Canada.

A41 The effectiveness of emergency cares practitioners working within existing emergency service models of care/2007/Emerg Med J/England.

A42 A before- and after intervention trial for reducing unexpected events during the intrahospital transport of emergency patients/2012/Am J Emerg Med/ Korea.

A43 Using an evidence-based care bundle to improve Thai emergency nurses' knowledge of care for patients with severe traumatic brain injury/2015/Nurse Educ Pract/Thailand. 
The reference code concerns the organization of bibliographic items that comprised the final sample of this research and represented by the letter " $A$ " (= article) followed by the corresponding Arabic numerals, which vary from 1 to 43. For example, the first article analysis is "A1".

According to Table 1, there were more descriptive studies ( $n=35 ; 81.4 \%)$, with a quantitative approach ( $n=32 ; 74.4 \%)$, classified as level of evidence $4(\mathrm{n}=35 ; 81.4 \%)$ and grade of recommendation $A$ $(n=40 ; 93.0 \%)$. As for the country where the research was conducted, there was a predominance of the United States ( $n=11 ; 25.6 \%)$ and Sweden $(n=5,11.6 \%)$.

Table 2 describes the aspects related to the components of the triad of Avedis Donabedian - structure, process, and the result, addressed by the studies analyzed.

With regard to the items shown in Table 2, it was found that the structure of emergency services to multiple trauma patients there was a predomination of the availability of equipment for performing

Table 2. Presentation of the elements related to Donabedian triad approached in the articles analyzed $(n=43), 2016$.

\section{Donabedian Triad (Code) \\ (In) Security Elements In Emergency Service (N; \%)}

Structure

(A2, A4-A10,

A13, A15-A16,

A19, A21-A22,

A24-A28,

A30-A35, A41,

A43)
Need of equipment for performing imaging and laboratory functioning exams $(n=18$; 41.9\%);

Need for effective and active continuing education with emphasis on staff training in support of advanced life to trauma $(n=13 ; 30.2 \%)$;

Human resources lack in the knowledge and skills ( $n=11 ; 25.6 \%)$;

Insufficient human resources $(n=9$; 20.9\%);

Material for intubation of all sizes and support for oxygen therapy $(n=8 ; 18.6 \%)$;

$18,6 \%) ;$ Basic medicine in an emergency - opioids, anesthetics, antibiotics ( $n=8$; $18.6 \%)$;

Availability of inpatient beds with enough numbers and in good condition $(n=7$; $16.3 \%)$;

\section{Donabedian Triad (Code)}

\section{(In) Security Elements In Emergency} Service (N; \%)

Availability of one heart monitor per bed $(n=6 ; 14.0 \%)$;

Physical space and material for sutures and dressings $(n=5 ; 11.6 \%)$;

Material for immobilization available in all sizes $(n=5 ; 11.6 \%)$;

Training of human resources to carry out screening $(n=4 ; 9.3 \%)$;

Availability of blood and blood products for transfusion ( $n=3 ; 7.0 \%)$;

Availability of stretchers for transport $(n=3$; 7.0\%);

Structure

(A2, A4-A10, A13, A15-A16, A19, A21-A22,

A24-A28, A30-A35, A41, A43)

Process

(A1-A4, A9-

15, A17-A18,

A20-A23,

A25-A29,

A31-A41,

A43)
Availability of personal protective equipment ( $n=3 ; 7.0 \%)$;

Material for enabling venous access $(n=3$; $7.0 \%)$

Chest tube tray available ( $n=1 ; 2.3 \%)$; Inexperience of managers when planning staff dimensioning for the emergency department $(n=1 ; 2.3 \%)$;

Waiting for physical space for the family $(n=1 ; 2.3 \%)$;

Availability of general surgery and neurosurgery staff during 24 hours, seven days a week ( $n=1 ; 2.3 \%)$;

Conditions of cleanliness and hygiene $(n=1$; $2.3 \%)$.

Availability of personal protective equipment ( $n=3 ; 7.0 \%)$;

Material for enabling venous access $(n=3$; 7.0\%);

Improvement in the screening process $(n=20 ; 46.5 \%)$;

The importance of the use of protocols or checklists to standardize screening $(n=9$; 20.9\%);

The importance of the use of protocols and guidelines for multiple trauma assistance $(n=9 ; 20.9 \%)$;

Improved communication between professionals ( $n=8 ; 18.6 \%)$;

Medical records ( $n=7 ; 16.3 \%)$;

Improved communication between patients and professionals ( $n=7 ; 16.3 \%)$;

Continuous monitoring of vital signs $(n=5$; $11.6 \%$;

Aid in the insertion and maintenance of endotracheal intubation $(n=4 ; 9.3 \%)$; 
Donabedian Triad (Code)

Process

(A1-A4, A9-

15, A17-A18,

A20-A23,

A25-A29,

A31-A41,

A43)
(In) Security Elements In Emergency Service (N; \%)

Application of techniques for bleeding contention ( $n=4 ; 9.3 \%)$;

Proper technique for the viability of venous access and fluid administration ( $n=4 ; 9.3 \%)$;

Patient identification ( $n=3 ; 7.0 \%)$;

Care in the administration of blood and blood products $(n=3 ; 7.0 \%)$;

Rating risk of falls ( $n=2 ; 4.7 \%)$;

Proper technique for the insertion and care of the urinary catheter $(n=2 ; 4.7 \%)$;

Primary stabilization of fractures $(n=2$;

4.7\%):

Maintaining the stretcher bars high $(n=1$; $23 \%)$;

Aseptic techniques for the prevention of infections ( $n=1 ; 2.3 \%)$;

No continuity of care between the prehospital and in-hospital ( $n=1 ; 2.3 \%)$;

Cardiopulmonar resuscitation ( $n=1 ; 2.3 \%)$; Use of algorithms to assess the need for transfusion of blood and blood products $(n=1 ; 2.3 \%)$.

Use of algorithms to assess the need for transfusion of blood and blood products $(n=1 ; 2.3 \%)$.

Great waiting time for care $(n=4 ; 9.3 \%)$;

Dissatisfaction of professionals regarding the care provided and the working conditions ( $n=4 ; 9.3 \%)$;

Hospital infection development $(n=3$; $7.0 \%)$;

Increased number of complications resulting from trauma $(n=3 ; 7.0 \%)$;

Result Low quality and effectiveness of care $(n=3$; (A3, A11, A14, 7.0\%);

A19, A21-A22, A26-A27, A30-A35 A38-A41)
High number of falls ( $n=2 ; 4.7 \%)$;

Increase in the number of adverse events $(n=2 ; 4.7 \%)$;

Dissatisfaction of patients about the care received $(n=2 ; 4.7 \%)$;

Reduction in mortality from bleeding after trauma events ( $n=2 ; 4.7 \%)$;

Waiting for time reduction for care $(n=2$; 4.7\%);

Reduction of the patient's length of stay in the emergency department $(n=1 ; 2.3 \%)$. imaging and laboratory functioning exams $(n=18$; $41,9 \%)$, the need for an effective and active continuing education with emphasis on staff training in support of advanced life to trauma ( $n=13 ; 30.2 \%)$ to improve the knowledge and skills of human resources ( $n=11 ; 25.6 \%)$.

Regarding the process, the largest number of analyzed articles aimed to the completion of screening in the emergency department $(n=20 ; 46.5 \%)$, use of protocols or checklists to standardize screening $(n=9 ; 20.9 \%)$ and the importance of using protocols and guidelines for assist the multiple trauma patient ( $n=9,20.9 \%)$.

Finally, the results highlighted the long waiting time of patients to treatment $(n=4 ; 9.3 \%)$ and dissatisfaction of professionals regarding the care provided and the working conditions $(n=4 ; 9.3 \%)$.

\section{Discussion}

The discussion of the results will be divided into three topics to facilitate understanding of the evidence found: Structure of the emergency service and patient safety; The care process and safe care to the multiple trauma patients; and the result of emergency care and safety of multiple trauma patients.

\section{The structure of the emergency service and patient safety}

Agreed with the triad proposed by Avedis Donabedian, the structure relates to the relatively stable characteristics of health institutions, such as physical, human, material, financial and organizational structure area [9]. Therefore, it is considered that the structure available in emergency services is directly related to patient safety. Since, for the effectiveness of safe care, is of paramount importance to the availability of human resources, and structural materials in quantity and quality to reduce the possibility of adverse events and contribute to the best multiple trauma patient's prognoses.

Therefore, it is essential that emergency units are in accordance with the recommendations in the cu- 
rrent legislation for the care to be safe: Decree $\mathrm{N}^{\circ}$ 2,048, of November 5, 2002 [14]; RDC Resolution $N^{\circ} 50$ of the National Health Surveillance Agency (ANVISA) of 21 February 2002 [15]; and RDC Resolution N $N^{\circ} 36$ of ANVISA, of 25 July 2013 [16].

According to the recommendations by the above legal reference, the structure of the emergency units must have a space of $12,0 \mathrm{~m} 2$ per bed, with a distance of $1 \mathrm{~m} 2$ between beds and wall, as well as enough room to maneuver the stretcher; a nursing station for every 12 observation beds; $8,0 \mathrm{~m} 2$ space for medical screening and/or nursing; sutures/ dressings room; special procedures room (invasive); spaces for circulation with a minimum width of 2,0m2; and outer space landing ambulances with $21,0 \mathrm{~m} 2$ covered area [15].

In addition, Brazilian law and international literature recommend that emergency rooms include two points of oxygen, a vacuum and a compressed air per bed (A5-A7, A10, A15), as well as bagvalve-mask device; oropharyngeal cannula package; suction probes; Oxygen bullets (A5-A7, A10, A15); portable or fixed vacuum (A5-A7, A15); material for venipuncture $(A 7, A 10, A 15)$, endotracheal intubation (A5-A7, A10, A15, A26, A21), dressing ( $A 5$, $A 9, A 13)$, small sutures (A5, A10) and immobilization material in all sizes (cervical collars, splints) (A5, A7, A10, A15, A26) [14-15].

Among the publications included in the final sample there were $25.6 \%$ (A4-A5, A10, A15, A18A19, A21-A22, A26-A27, A33) demonstrating the importance of these professionals developing skills and well-founded knowledge, to provide safe care to the multiple trauma patients. In this regard, regular training of the trauma team is considered essential for the emergency care and essential to reduce the time required for a complete assessment of the patient. Therefore, the application of knowledge based on standardized and systematic principles outlined in the protocols and trauma care guidelines have been associated with the best care (3-A) [18].
Also, the need for the involvement of different professionals and experts (general surgeons, neurosurgeons, nurses, oral and maxillofacial surgeons) in the care of victims of traumatic emergencies, and able to work in a team, as described in 2.3\% (A30) of the evidence analyzed in this research. This is considered crucial in critical situations, such as emergency departments and trauma, in order to promote improvements in clinical parameters and patient safety, with an emphasis on speed of service (4-A) [19], since that time between the traumatic event and the service is very importance when considering the patient's chances of survival.

Thus, the challenges associated with poor infrastructure, inadequate human resources and/or overburdened health systems, the access to emergency care become limited (4-B, 4-A) [20-21]. This overload or emergency room overcrowding is a reality that have complex causes related to insufficient hospital beds (A6, A21, A26-A27, A30, A33-A34) and human resources (A6, A8, A10, A15 , A21, A27, A28, A30, A34) and lack of an effective health control network (4-B, 4-B, 4-A) [22-24], as the above by $16.3 \%$ analyzed studies in this research.

Meanwhile, the evaluation of the structure is based on the premise that adequate physical facilities tend to result in more qualified [25] and safe processes for the patient and the professional. The deficits in infrastructure, basic material, and qualified human resources adversely affect the ability to provide quality health care (1-B) [5].

\section{The care process and safe care to the multiple trauma patients}

Donabedian [9] describes the process as a set of activities in the production of goods and services. In the health sector, it is associated with relations between professionals and patients from the search for a diagnosis, treatment and appropriate and safe care.

In this research, the process corresponds to the nursing actions to ensure the safety of multiple trauma patients, and there were predominated the as- 
pects related to the need for improvement in screening ( $A 2$, A4, A13, A15, A21-A22, A25-A28, A31A32, A41); the importance of using protocols and guidelines for compliance with multiple trauma $(A 2$, A4, A13, A15, A21-A22, A27, A32, A41); improving communication in the emergency department (A4, A20-A21, A23, A25, A27-A28, A31-A35, A41); the medical record $(A 2, A 12, A 21, A 25, A 32, A 34$, $A 36)$; continuous monitoring of vital signals (A13, A25-A26, A34, A44); the aid in insertion and maintenance of intubation (A13, A26, A36, A44); and techniques for containment bleeding (A3, A9, A13, A36, A40).

Regarding the screening, it is necessary to be held with quality to ensure that life-threatening injuries are not neglected, and the patient receives proper care to his medical condition to contribute to a better prognosis (4-A) [26].

Therefore, the use of protocols or checklists to standardize the screening in the multiple trauma patients care is considered extremely valuable. Usually, this type of instrument incorporates physiological, anatomical criteria, injury mechanism and special considerations (4-B) [27].

The guidelines for screening of injured patients involve a gradual approach designed to identify serious injury as early as possible from pre-hospital care: 1) evaluation of vital signs and Glasgow coma scale (physiological criteria); 2) identification of visible injuries, as penetrating, crushing or long bone fractures (anatomical criteria); 3) recognition of the possible mechanisms of injury, such as traffic accidents or falls from a height; and 4) investigation of complicating factors, such as anticoagulants, involvement of children or the elderly, burned or pregnant patients (special considerations) (4-A) [28].

Also, another type of screening that allows the safety of the patient in the emergency department is the evaluation of the risk of falls, as recommended by A1. The ability to accurately identify patients with this type of risk in the emergency service is the first step to preventing damage and avoid prolon- ged length of stay in hospitals. Fall prevention is a process consisted of two steps: correct evaluation of fall risk and use of effective prevention strategies (4-A) [29], as elevation grids and use of belts in the patient stretchers transport.

The application of protocols is also recommended for the care of multiple trauma patients. That is, an emergency unit should include a standard approach for all patients who need acute care such as evaluation and interventions for establishing airways, breathing and circulation; a continuous check of vital signs; general physical evaluation of the patient; bleeding control; immobilization and evaluation of potential damage (1-B) [5].

Similarly, the use of protocols is also indicated for the transfusion of blood and/or blood products. Therefore, for the transfusion process being safe, it is necessary preliminarily to confirm the identity of the patient and compatible with the product to be infused (red blood cells, platelets, clotting factors, fresh frozen plasma, white blood cells) (2-A) [30].

Also, the blood component should be maintained for at most 30 minutes at room temperature before starting the infusion. Subsequently, cleaning of the catheter with saline (2-A) is indispensable [30].

Thus, it is emphasized that the standardization of procedures has a positive effect on the quality and safety of the emergency care of patients with multiple traumas (4-A) [31]. As part of the evolution of patient safety, human interests in protocolbased interventions, guidelines and checklists are in evidence to standardize the verification procedures needed and act as a cognitive aid to ensure the quality of care to critically ill patients in the shortest time possible. The expectation is that these tools contribute in the care of health and support the performance of the workforce and provide more effective defenses against systemic adverse events and avoidable harm (4-A) [32].

The adherence to protocols and checklists significantly collaborate to patient safety (4-A) [33] and 
help in the quality of the complete patient's medical record (4a-A) [34].

Therefore, in line with the National Policy on Emergency Care, Ordinance 2,048/2002 of the Ministry of Health, the emergency units must have a medical record for each patient with the complete information of the clinical picture and their evolution, written clear and precise, dated and signed by the professional responsible for the care. This record should contain minimal information, such as patient identification; medical history; initial evaluation; indication of the surgical procedure, and if applicable, description of the surgical procedure; its developments, requirements and conditions at discharge or transfer [14].

The quality of such records is a growing concern in health institutions, since insufficient information affects and interpose to the quality of care, especially when related to the identification data, when incomplete, strongly compromising patient safety (4-A) [35].

Also, the fact that incomplete notes and failures in multi-professional team records are factors that prevent the traceability information in the documents contributes to the non-continuity of care and the insecurity of the patient (4-A) [36].

Thus, a study (4-A) [37] corroborates the findings of this research to demonstrate that communication is not always effective in the emergency department, and this reality is due to high noise levels in the sector and inadequate medical records. Thus, the deficit in communication among professionals has resulted in the lack of knowledge of the staff about the activities performed and exchange of roles and responsibilities due to the lack of direction.

Implementing procedures to enhance communication between professionals should be standardized as soon as possible to promote the efficiency of care in the emergency department, to minimize the time to perform critical patient care plan (3-B, 3-A) [38-39].
Furthermore, effective communication among health professionals has been associated with simplification of teamwork, increased productivity, reduced costs and improved care (4-A) [40]. In the meantime, it is considered that a clear and complete communication is vital to ensure patient safety and quality of care (3-A) [41].

\section{The result of emergency care and safety of multiple trauma patients}

Donabedian [9] describes the results as achieving the target characteristics of products or services. They show the effects of health care, that is, the condition of the patient to be discharged from the health institution and if his expectations were met.

In this sense, this scoping review included studies that have referred mainly to the following results: long waiting time for care (A9-A10, A22, A36), dissatisfaction of professionals regarding the care provided and the working conditions (A9, A16, A14, A37), hospital infection development (A3, A27, A40), increased number of complications resulting from trauma (A3, A27, A40) and low quality and effectiveness of care (A19, A21, A27).

Thus, it is emphasized that the available structure and the process performed in the emergency care for the multiple trauma directly influence the results. Thus, authors (1-B) [5] acknowledges that the lack of trained health professionals, deficiencies in physical space and inadequate equipment for emergency care in health services contribute to delays in the care, as reflected in the quality of care.

Early treatment in emergency situations is one of the essential interventions for a good prognosis. However, the long waiting time for care creates delays in the treatment of injuries and can result in increased morbidity and mortality, adverse events and complications of trauma (4-A 3-B 4-A) [42-44].

Therefore, the working conditions notably offered by health services can contribute to the (in) satisfaction of professionals as well as for the (in) safe care, because of the inability give a terminal care and 
with low risk of damage. This dissatisfaction may be intrinsically associated with carrying out work with no affinity; the "do not like what you do"; and/or non-solvability of care (4-A) [45].

Similarly, these professionals often struggle daily to cope with high workloads associated with trying to manage a variety of other human factors that can compromise the emergency team performance and patient safety, for example: work system organization; organizational constraints (no response to contractual incentives and increased demand for care to critically ill patients); and availability of limited resources (deficiency in the distribution of financial and/or human resources) (4-B) [46].

Given the complexity of the emergency service and clear structural and procedural difficulties, the nursing staff should aim to a safe care and without risk or harm to patients (4-A) [47], so that the care provided is effective and with quality.

This study included the analysis of articles published in international databases about the association between the triad structure-process-result proposed by Avedis Donabedian and safe care to the multiple trauma patients.

From this, it is concluded that the structure of emergency services is not able to compromise the security of critically ill patients. Regarding the process, there was an emphasis on the nursing actions related to screening and the importance of using protocols and guidelines for compliance with multiple trauma. The results showed that there was a great time to wait for the provision of emergency care and the dissatisfaction of professionals regarding the care provided and the working conditions.

This research brings as a contribution the basis of the scientific evidence for the construction of a protocol to assess the safe care of multiple trauma patients in the emergency department, to collaborate to reduce adverse events and improve the quality of health services.

\section{Conflicts if interest}

As authors of this paper, we declare that there was not conflicts of interest.

\section{References}

1. Lendrum RA, Lockey DJ. Trauma system development. Anaesthesia. 2013 Jan; 68(3):30-9. doi: http://dx.doi.org/10.1111/ anae.12049

2. World Health Statistics [Internet]. 2011 [cited 2016 Jun 21] Available from: http://www.who.int/whosis/whostat/2011/en/ indext.html

3. Sakran JV, Greer SE, Werlin E, McCunn M. Care of the injured worldwide: trauma still the neglected disease of modern society. Scand J Trauma Resusc Emerg Med. 2012 Sep; 20(64):1-6. doi: http://dx.doi.org/10.1186/1757-7241-20-64

4. Groenestege-Kreb TD, van Maarseveen O, Leenen L. Trauma team. Br J Anaesth. 2014 Jun; 113(2):258-65. doi: http://dx.doi. org/10.1093/bja/aeu236

5. Burke TF, Hines R, Ahn R, Walters M, Young D, Anderson RE, et al. Emergency and urgent care capacity in a resource-limited setting: an assessment of health facilities in western Kenya. BMJ Open. 2014; 4(9):e006132. doi: http://dx.doi.org/10.1136/ bmjopen-2014-006132

_6. Ajeigbe D, McNeese-Smith D, Leach LS, Phillips LR. Nursephysician teamwork in the emergency department: impact on perceptions of job environment, autonomy, and control over practice. J Nurs Adm. 2013 Sep; 43(3):142-8. doi: http://dx.doi. org/10.1097/NNA.0b013e318283dc23

7. Zohar D. Safety climate in industrial organizations: theoretical and applied implications. J Appl Psychol. 1980 Mar; 65(1):96102. doi: http://dx.doi.org/10.1037/0021-9010.65.1.96

8. El Sayed MJ. Measuring quality in emergency medical services: a review of clinical performance indicators. Emerg Med Int. 2012 Feb; 2012:1-7. doi: http://dx.doi.org/10.1155/2012/161630

9. Donabedian, A. Evaluating the Quality of Medical Care. Milbank Mem. Fund Quart, Part 2, 1966 Oct; 44(3):166-206. doi: http:// dx.doi.org/10.1111/j.1468-0009.2005.00397.x

10. Arksey H, O'Malley L. Scoping studies: towards a methodological framework. Int J Soc Res Methodol. 2005 Feb; 8(1):19-32. doi: http://dx.doi.org/10.1080/1364557032000119616

11. The Joanna Briggs Institute. Joanna Briggs Institute Reviewers' Manual: 2015 edition / Supplement. South Austrália: The University of Adelaide; 2015.

12. The Joanna Briggs Institute [Internet]. Levels of Evidence. South Austrália: The University of Adelaide; 2013 [cited 2016 Jul 02]. Available from: http://joannabriggs.org/jbi-approach. html\#tabbed-nav=Levels-of-Evidence

13. The Joanna Briggs Institute [Internet]. Grades of Recommendation. South Austrália: The University of Adelaide; 2013 [cited 2016 Jul 02]. Available from: http://joannabriggs.org/ jbi-approach.html\#tabbed-nav=Grades-of-Recommendation 
14. Ministério da Saúde (Br). Política nacional de atenção às urgências. 3. ed. Brasília: Editora do Ministério da Saúde; 2006.

15. Ministério da Saúde (Br). Agência Nacional de Vigilância Sanitária. Resolução - RDC n 50, de 21 de fevereiro de 2002. Dispõe sobre o Regulamento Técnico para planejamento, programação, elaboração e avaliação de projetos físicos de estabelecimentos assistenciais de saúde. Brasília; 2002

16. Ministério da Saúde (Br). Ministério da Saúde. Agência Nacional de Vigilância Sanitária. Resolução - RDC n 36, de 25 de julho de 2013. Institui ações para a segurança do paciente em serviços de saúde e dá outras providências. Brasília; 2013.

17. Lambrou P, Papastavrou E, Merkouris A, Middleton N. Professional environment and patient safety in emergency departments. Int Emerg Nurs. 2015 Apr; 23(2):150-5. doi: 10.1016/j.ienj.2014.07.009

18. Tsang B, McKee J, Engels PT, Paton-Gay D, Widder SL. Compliance to advanced trauma life support protocols in adult trauma patients in the acute setting. World J Emerg Surg. 2013 Jan; 8(1):1-7. doi: 10.1186/1749-7922-8-39.

19. Khademian Z, Sharif F, Tabei SZ, Bolandparvaz S, Abbaszadeh A, Abbasi HR. Teamwork improvement in emergency trauma departments. Iran J Nurs Midwifery Res [Internet]. 2013 Jul [cited 2016 Jul 09]; 18(4):333-9. Available from: http://www. ncbi.nlm.nih.gov.ez18.periodicos.capes.gov.br/pmc/articles/ PMC3872871/

20. Hsia R, Mbembati N, Macfarlane S, Kruk ME. Access to emergency and surgical care in sub- Saharan Africa: the infrastructure gap. Health Policy Plann [Internet]. 2012 May; 27(3):234-44. doi: http://dx.doi.org/10.1093/heapol/czr023

21. Riviello ED, Letchford S, Achieng L, Newton MW. Critical care in resourcepoor settings: lessons learned and future directions. Crit Care Med. 2011 Apr; 39(4):860-7. doi: http://dx.doi. org/10.1097/CCM.0b013e318206d6d5

22. Kocher KEK, Meurer WJW, Desmond JSJ, Nallamothu BKB. Effect of testing and treatment on emergency department length of stay using a national database. Acad Emerg Med. 2012 May; 19(5):525-34. doi: http://dx.doi.org/10.1111/j.15532712.2012.01353.x

23. Pitts, S.R., Pines, J.M., Handrigan, M.T., Kellermann, A.L. National trends in emergency department occupancy, 2001 to 2008: effect of inpatient admissions versus emergency department practice intensity. Ann Emerg Med. 2012 Dec; 60:(6)679-86. doi: http://dx.doi.org/10.1016/j.annemergmed.2012.05.014

24. Travaglia JF, Spigelman AD, Braithwaite J. Clinical governance: a review of key concepts in the literature. Clin Gov. 2011; 16(1):6277. doi: http://dx.doi.org/10.1108/14777271111104592

25. Donabedian A. The quality of care: how can it be assessed? J Am Med Assoc. 1988 Sep; 260(12):1743-8.

26. Sunyoto T, Van den Bergh R, Valles P, Gutierrez R, Ayada L, Zachariah $R$, et al. Providing emergency care and assessing a patient triage system in a referral hospital in Somaliland: a crosssectional study. BMC Health Services Research. 2014; 14:531-7. doi: http://dx.doi.org/10.1186/s12913-014-0531-3
27. Brown JB, Stassen NA, Bankey PE, Sangosanya AT, Cheng $\underline{\mathrm{JD}}$, Gestring ML. Mechanism of injury and special consideration criteria still matter: an evaluation of the National Trauma Triage Protocol. J Trauma. 2011 Jan; 70(1):38-44. doi: http://dx.doi. org/10.1097/TA.0b013e3182077ea8

28. Sasser SM, Hunt RC, Faul M, Sugerman D, Pearson WS, Dulski $T$, et al. Centers for Disease Control and Prevention (CDC). Guidelines for field triage of injured patients: recommendations of the National Expert Panel on Field Triage, 2011. MMWR Recomm Rep [Internet]. 2012 [cited 2016 Jul 30]; 61(RR-1): 1-20. Available from: http://web.a-ebscohost-com.ez18.periodicos. capes.gov.br/ehost/pdfviewer/pdfviewer?sid=d1cf2267-20904ba9-adf9-b49410fcd46b\%40sessionmgr4009\&vid=1\&h $\underline{i d}=4204$

29. Alexander D, Kinsley TL, Waszinski C. Journey to a safe environment: fall prevention in an emergency department at a level I trauma center. J Emerg Nurs. 2013 Jan; 39(4):346-52. doi: http://dx.doi.org/10.1016/j.jen.2012.11.003

30. Conselho Regional de Enfermagem de São Paulo. Rede Brasileira de Enfermagem e Segurança do Paciente. 10 passos para a segurança do paciente. São Paulo: COREN - SP; 2010.

31. Adib-Hajbaghery M, Maghaminejad F, Rajabi M. Efficacy of prehospital spine and limb immobilization in multiple trauma patients. Trauma Mon. 2014 Aug; 19(3): e16610. doi: http:// dx.doi.org/10.5812/traumamon.16610

32. Rosen MA, Pronovost PJ. Advancing the use of checklists for evaluating performance in health care. Acad Med. 2014 Jul; 89(7):963-5. doi: http://dx.doi.org/10.1097/ ACM.0000000000000285

33. di Martino P, Leoli F, Cinotti F, Virga A, Gatta L, Kleefield $S$, et al. Improving vital sign documentation at triage: an emergency department quality improvement project. J Patient Saf. 2011 Mar; 7(1):26-9. doi: http://dx.doi.org/10.1097/ PTS.0b013e31820c9895

34. Jönsson K, Fridlund B. A comparison of adherence to correctly documented triage level of critically ill patients between emergency department and the ambulance service nurses. Int Emerg Nurs. 2013 Jul; 21(3):204-9. doi: http://dx.doi. org/10.1016/j.ienj.2012.07.002

35. Silva JA, Grossi ACM, Haddad MCL, Marcon SS. Avaliação da qualidade das anotações de enfermagem em unidade semiintensiva. Esc Anna Nery Rev Enferm. 2012 Jul; 16(3):576-81. doi: http://dx.doi.org/10.1590/S1414-81452012000300021

36. Kobayashi RM, Silva ABV, Ayoub AC. Gerenciando dificuldades para acreditação hospitalar em hospital cardiovascular. Rev Rene [Internet]. 2010 Oct [cited 2016 Jul 30]; 11(4):19-28. Available from: http://www.revistarene.ufc.br/vol11n4 pdf/a02v11n4.pdf

37. Murphy MM, Edwards CM, Seggie JZJ, Curtis K. Emergency department trauma redesign in a level 1 trauma centre. Australas Emerg Nurs J. 2011 Feb; 14(1):50-8. doi: http://dx.doi. org/10.1016/j.aenj.2010.10.003

38. Mazzocato P, Forsberg $H$, Schwartz $U$. Team behaviors in emergency care: a qualitative study using behavior analysis of what makes teams work. Scand J Trauma Resusc Emerg Med. 2011 Nov; 19(1):70-76. doi: http://dx.doi.org/10.1186/1757$\underline{7241-19-70}$ 
39. Martin HA, Ciurzynski SM. Situation, background, assessment, and recommendation-guided huddles improve communication and teamwork in the emergency department. J Emerg Nurs. 2015 Nov; 41(6):484-8. doi: http://dx.doi.org/10.1016/j. jen.2015.05.017

40. Leonard M, Frankel A. Role of effective teamwork and communication in delivering safe, high-quality care. Mt Sinai J Med. 2011 Nov; 78(6):820-826. doi: http://dx.doi.org/10.1002/ msj. 20295

41. Jones F, Podila P, Powers $C$. Creating a culture of safety in the emergency department: the value of team working training. J Nurs Adm. 2013 Apr; 43(4):194-200. doi: http://dx.doi. org/10.1097/NNA.0b013e31828958cd

42. Crandall M, Sharp D, Unger E, Straus D, Brasel K, Hsia R, et al. Trauma deserts: distance from a trauma center, transport times, and mortality from gunshot wounds in Chicago. Am J Public Health. 2013 Jun; 103(6):1103-9. doi: http://dx.doi.org/10.2105/ AJPH.2013.301223

43. McCoy CE, Menchine M, Sampson S, Anderson C, Kahn C. Emergency medical services out-of-hospital scene and transport times and their association with mortality in trauma patients presenting to an urban Level I trauma center. Ann Emerg Med. 2013 Feb; 61(2):167-74. doi: http://dx.doi.org/10.1016/j. annemergmed.2012.08.026

44. Calvello EJB, Broccoli M, Risko N, Theodosis C, Totten VY, Radeos MS, et al. Emergency care and health systems: consensus-based recommendations and future research priorities. Acad Emerg Med. 2013 Dec; 20(12):1278-88. doi: http://dx.doi.org/10.1111/ acem.12266

45. Lima L, Pires DEP, Forte ECN, Medeiros F. Satisfação e insatisfação no trabalho de profissionais de saúde da atenção básica. Esc Anna Nery Rev Enferm. 2014 Jan; 18(1):17-24. doi: http://dx.doi. org/10.5935/1414-8145.20140003

46. Bowie P, Halley L, McKay J. Laboratory test ordering and results management systems: a qualitative study of safety risks identified by administrators in general practice. BMJ Open. 2014 Feb; 4(2): e004245. doi: http://dx.doi.org/0.1136/bmjopen-2013-004245

47. Souza FT, Garcia MC, Rangel PPS, Rocha PK. Percepção da enfermagem sobre os fatores de risco que envolvem a segurança do paciente pediátrico. Rev Enferm UFSM. 2014 Jan; 4(1):15262. doi: http://dx.doi.org/10.5902/217976928781
Publish in International Archives of Medicine

International Archives of Medicine is an open access journal publishing articles encompassing all aspects of medical science and clinical practice. IAM is considered a megajournal with independent sections on all areas of medicine. IAM is a really international journal with authors and board members from all around the world. The journal is widely indexed and classified Q2 in category Medicine. 